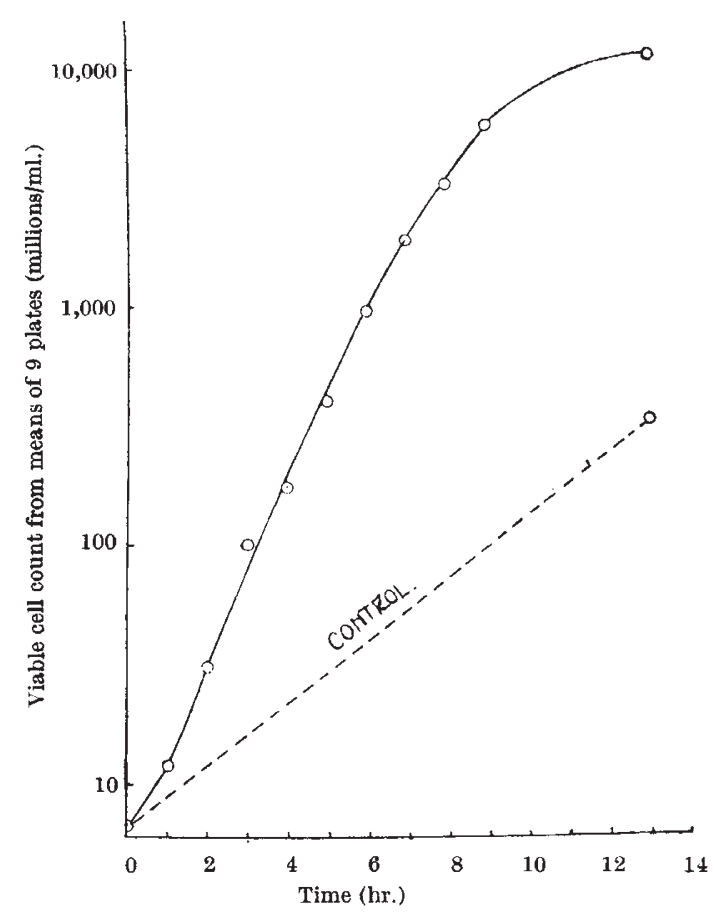

of starter culture. Compressed air, sterilized by passing through sulphuric acid in a stainless steel pressuretank, over dry sterile charcoal in a $3 \mathrm{ft}$. $\times 2 \frac{1}{2} \mathrm{in}$. steel cylinder and through a sterilized slag wool filter, was passed through the medium at about 0.75 cu. ft. per minute; this corresponded to a pressure of 4-6 lb. per sq. in. at the compressor end of the system. The growth approached its maximum at about $9 \mathrm{hr}$. and was harvested at $13 \mathrm{hr}$.

The growth of such a culture of Bact. coli is shown in the accompanying graph. In this example, the viable count of the aerated culture was thirty-four times greater than that of the control. In order to ensure that the full possibilities of the control medium had been exploited, it was incubated for a further $12 \mathrm{hr}$. Comparison of opacities after this showed a difference of twenty-three times between the two cultures, and the numbers of cells per $\mathrm{ml}$. as estimated by opacity tubes was 24,000 million in the aerated culture and 1,100 million in the control. RICHARD S. ROBERTS

Evans Biological Institute,

Runcorn, Cheshire.

Dec. 8.

\section{Formation of a Green Oxidation-Reduction Indicator in Plant Extracts}

Cerrats plants have been found to yield a thermostable system which slowly produces a blue-green pigment by atmospheric oxidation. After acidifying with hydrochloric acid, the green colour was changed to red. If the first green solution was allowed to stand, the green changed back to the original yellowish colour, with the exception of the surface layer, which remained greenish. Thus the above green pigment may serve as a natural indicator in various physiological investigations; its chemical nature is now under investigation.
An extract of the substance was prepared as follows. Yellow peelings of ripening 'Victoria' plums were put into boiling water, and the heating was discontinued immediately. After about thirty minutes, the extract was decanted; powdered sodium bicarbonate was added to bring the $p H$ to 8-9, and the liquid was shaken with air. This produces the green pigment.

The same reaction was shown in extracts from the leaves of some other plants; as, for example, Sanguisorba officinalis, Achillea millefolium, Convolvulus arvensis, Solidago virgo aurea, Taraxacum officinale and Sonchus sp. Also yellow petals of these two latter showed a similar reaction.

East Malling Research Station,

$$
\text { ANTONI KozLowskI }
$$

$$
\text { Kent. }
$$

\section{A Branched Pipette}

A BRANCHED pipette similar to that described by Swallow ${ }^{1}$ has been in use in my laboratory here since 1939. This was designed by me to expedite measurement of small quantities of liquid for rapid soil analysis, and a number were made by a London firm of glassblowers. In this pattern, the branches are Y-shaped and approximately symmetricel. Besides the advantage of rapid measurement, they are easily cleaned by directing a jet of water through the opening $A$ and are also convenient to hang up in a hook or through a hole in a shelf.

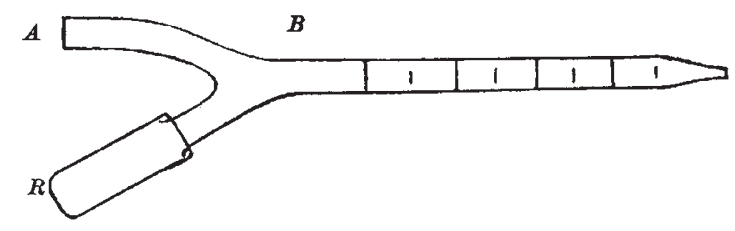

In a slight variation of the pattern, the tube is expanded at $B$ and is ground to fit the mouth of a bottle containing a liquid in frequent use. A loosefitting cap is put over $A$ if the liquid is volatile or is not in a situation protected from dust.

The parallel-sided rubber bulb, $R$, is preferable to the ordinary pear-shaped bulb.

H. W. GARDNER

Hertfordshire Institute of Agriculture, Oaklands,

St. Albans, Herts.

'Swallow, A. J., Nature, 165, 249 (1950).

\section{Potato Tuber Eelworm and Iris Bulbs}

For the past twenty-five years the identity of the nematode causing disease in bulbous irises has been in doubt. Investigations carried out in this Department during the past two years have proved conclusively that the potato tuber eelworm, Ditylenchus destructor Thorne, 1945, also infests bulbous irises belonging to Dutch, English and Spanish varieties. A full account of the investigations is being published elsewhere.

Nematology Department,

$$
\text { J. BASI, Goodey }
$$

Rothamsted Experimental Station, Harpenden, Herts. March 13. 